Special issue of the 3rd International Conference on Computational and Experimental Science and Engineering (ICCESEN 2016)

\title{
Radiation Shielding Properties of Some Composite Panel
}

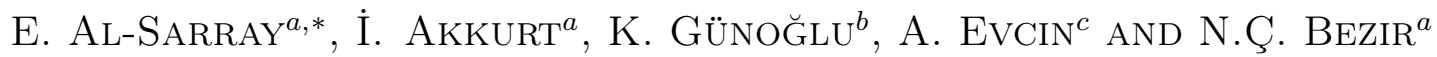 \\ ${ }^{a}$ Süleyman Demirel University, Science and Art Faculty, Department of Physics, Isparta, Türkey \\ ${ }^{b}$ Suleyman Demirel University, Technical Vocational School, Isparta, Turkey \\ ${ }^{c}$ Afyon Kocatepe Üniversity, Engineering Faculty, Material Science and Engineering, Afyonkarahisar, Türkey
}

With the discovering atomic nucleus, nuclear science started to be used in different fields and researcher focused on radiation protection as it is dangerous for human cell. Thus radiation physics and materials development becomes one of the important subject in science for this purposes. The developed material should be used for radiation shielding. In this work gamma ray shielding properties of some composite materials produced by polymer have been investigated.

DOI: 10.12693/APhysPolA.132.490

PACS/topics: radiation protection, composite material, radiation measurement

\section{Introduction}

Polymers are high molecular weight compounds composed of units called monomers. Numerous molecules are regularly attached to each other by chemical bonds and form polymers. Polymers are used in many areas such as building materials, adhesives, electronic tool parts, insulating materials, metal materials, insulation materials, textile and paper industries.

The development of technology radiation is being started to be used in a variety of different fields such as industrial, nuclear power stations, particle accelerators and medical hospitals and thus radiation protection becomes important. The radiation has hazardous effects for human health. In this case protecting from undesirable radiation is a necessity for human health. Although there are three ways for radiation protection, shielding of the radiation is the most commonly used method. As this subject is very important for human health, one can find many different studies on the linear attenuation coefficient for different materials. El-Sayed et al. performed experimental and theoretical studies on the linear attenuation coefficients for fibre-plastic composites [1]. Akkurt et al. determined the linear attenuation coefficients for including the effect of the addition of marble to the concretes in terms of radiation protection [2]. Baltas et al. determined mass attenuation coefficients of $\mathrm{YBaCuO}$ and $\mathrm{BiPbSrCaCuO}$ superconductors at 511 , 661, and $1274 \mathrm{keV}$ energies [3]. Many different studies on the linear attenuation coefficient were performed for different materials (e.g. polymer, alloy, steel, colemanite, etc.) $[4-12]$.

In the present work, photon attenuation coefficients of some composites were investigated for different gamma energies $(662,1173$, and $1332 \mathrm{keV})$ by using different point radioactive sources $\left({ }^{137} \mathrm{Cs}\right.$ and $\left.{ }^{60} \mathrm{Co}\right)$.

*corresponding author; e-mail: esraa.alsaray@outlook.com

\section{Material and method}

In this study some polymeric composite materials were produced and radiation shielding properties were measured. Barite has been used in different rate of $0 \%, 10 \%$, $20 \%, 30 \%, 40 \%$, and $50 \%$ in the composite. Six samples were prepared and mixing different proportions and, mixing each sample individually, consisted of polymer crystals, epoxy and barite. A mold for material as seen was cleaned firstly to product composite. Teknobond 300 (liquid diglycidyl ether of biphenol - A) was used as matrix material in fabrication of different specimens epoxy resin along with hardener. Epoxy resin has modulus of $3.42 \mathrm{GPa}$, and possesses density of $1100 \mathrm{~kg} / \mathrm{m}^{3}$. For processing the mix ratio (by weight) of epoxy resin (2 parts) and hardener (1 part) were used as specified. The required mixture of resin and hardener were made by mixing them in parts in a beaker by stirring the mixture in a beaker by a rod taking into care that no air should be entrapped inside the solution [13].

The photon attenuation coefficients $(\mu)$ of composites were measured at the photon energies of 662,1173 , and $1332 \mathrm{keV}$ obtained from ${ }^{137} \mathrm{Cs}$ and ${ }^{60} \mathrm{Co} \gamma$-ray sources, respectively. The measurements have been performed using a low level gamma counting spectrometer including a $3^{\prime \prime} \times 3^{\prime \prime} \mathrm{NaI}(\mathrm{TI})$ detector by ORTEC Inc., connected to a multichannel pulse height analyser [14]. The necessary power for the detector as well as the acquisition of gamma spectra was achieved by an integrated spectroscopic system. Schematic view of the experimental setup is displayed in Fig. 1. This system is controlled by a personal computer. The control of acquisition parameters and analysis of the collected spectra are carried out using MAESTRO-32 (version 6.06) software package.

The photon attenuation coefficients have been evaluated comparing $N$ and $N_{0}$, which are the measured count rates in detector, respectively, with and without the absorber of thickness $x(\mathrm{~cm})$

$$
N=N_{0} \mathrm{e}^{-\mu x} \text {. }
$$

$\gamma$-rays spectra obtained from ${ }^{137} \mathrm{Cs}$ and ${ }^{60} \mathrm{Co}$ sources are displayed in Fig. 2, where attenuated $(N)$ and unatten- 


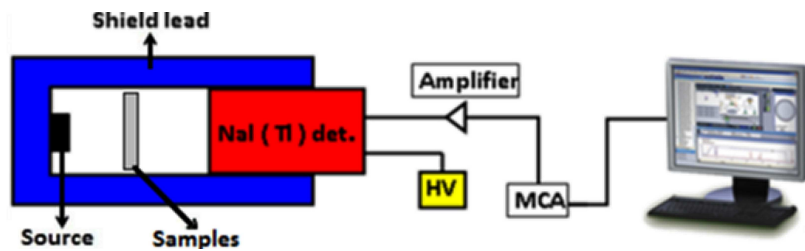

Fig. 1. Schematic view of gamma spectrometer and electronic units.

uated $\left(N_{0}\right) \gamma$-rays at 662,1173 , and $1332 \mathrm{keV}$ can be clearly seen.

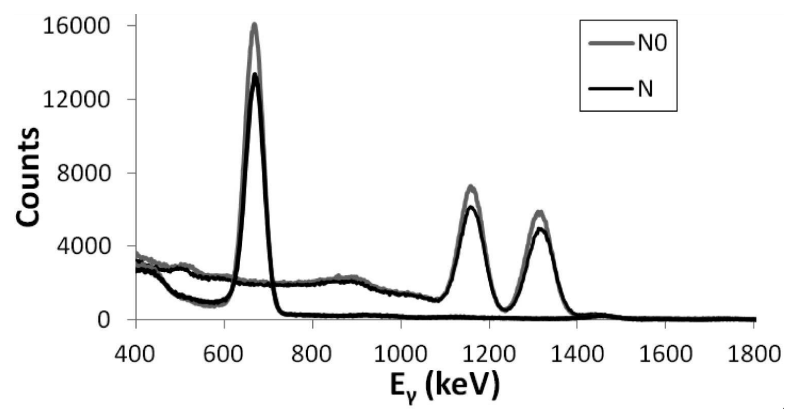

Fig. 2. Attenuated and unattenuated $\gamma$-rays spectra obtained from ${ }^{137} \mathrm{Cs}$ and ${ }^{60} \mathrm{Co}$ sources.

\section{Results and discussion}

The photon attenuation coefficients for 6 different types composites have been obtained using gamma spectrometer. The all collected results are shown in Fig. 3. In Figs. 4-6 the photon attenuation coefficients are displayed as a function of barite rate in composite for 662,1173 , and $133 \mathrm{keV}$ energy, respectively. It can be clearly seen from those figures that there is linearly increasing relation between barite rate and the linear attenuation coefficients. $R^{2}$ are about over $90 \%$ for all energies.

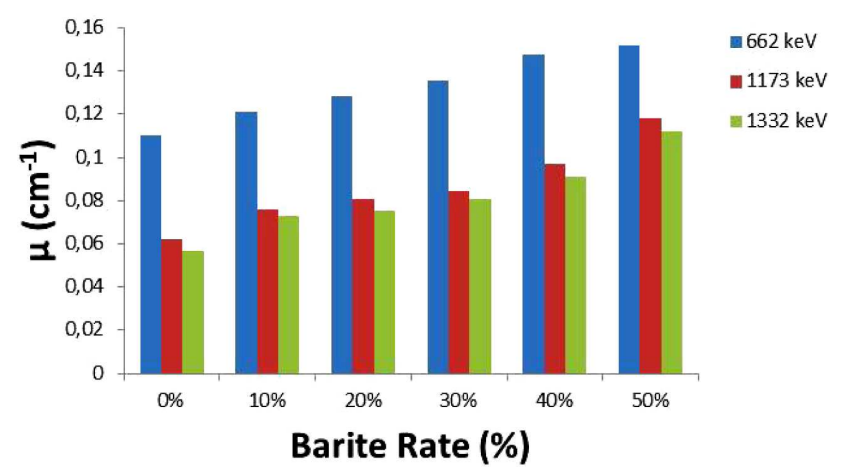

Fig. 3. Linear attenuation coefficients as a function of barite rate in composite.

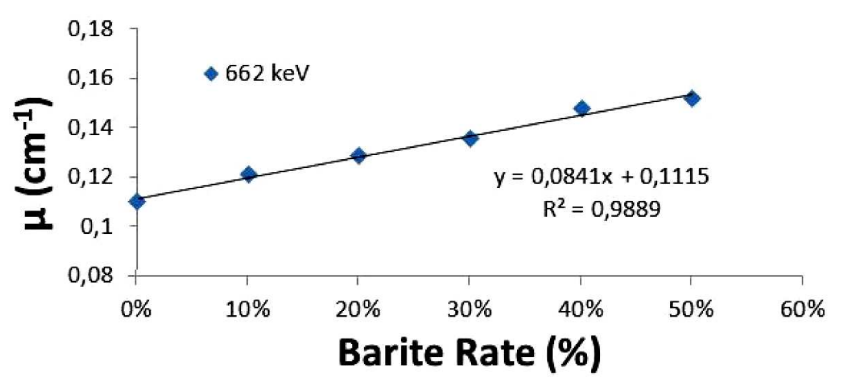

Fig. 4. Photon attenuation coefficients as a function of barite rate for $662 \mathrm{keV}$.

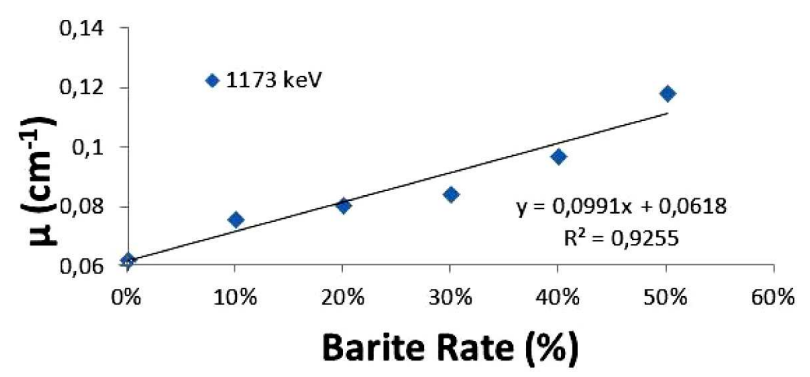

Fig. 5. Photon attenuation coefficients as a function of barite rate for $1173 \mathrm{keV}$.

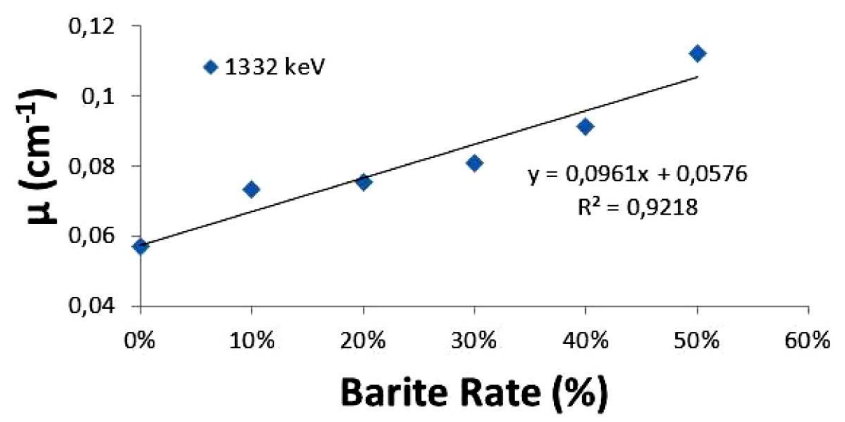

Fig. 6. Photon attenuation coefficients as a function of barite rate for $1332 \mathrm{keV}$.

\section{Conclusions}

The measurement has shown that the barite is an important material to shield gamma rays. With the increasing barite rate in composite material, the linear attenuation coefficients are also increased. This leads to that barite which its reserve is high in Turkey can be important mining source to be used in radiation shielding and this also leads to contribute to national economy of barite. Surely further research should be carried out to find out more suitable shielding materials. 


\section{References}

[1] A. El-Sayed, M.A.M. Ali, M.R. Ismail, Radiat. Phys. Chem. 66, 185 (2003).

[2] I. Akkurt, R. Altindag, K. Günoğlu, H. Sarıkaya, Ann. Nucl. En. 43, 56 (2012).

[3] D.Y. Stewart, P.F. Harrison, B. Morgan, Y. Ramachers, Nucl. Instrum. Methods Phys. Res. A 571, 651 (2007).

[4] J.C. Osborn, T. Ersez, G. Braoudakis, Physica B 385-386, 1321 (2006).

[5] A. Akkas, A.B. Tugrul, B. Buyuk, A.O. Addemir, M. Marsoglu, B. Agacan, Acta Phys. Pol. A 128, B-176 (2015).

[6] C. Zeitlin, S.B. Guetersloh, L.H. Heilbronn, J. Miller, Nucl. Instrum. Methods Phys. Res. B 252, 308 (2006).
[7] K. Okuno, Radiat. Prot. Dosim. 115, 259 (2005).

[8] I. Akkurt, A. Calik, H. Akyıldırım, Nucl. Eng. Des. 241, 55 (2011)

[9] O. Gurler, U. Akar Tarim, Acta Phys. Pol. A 130, 236 (2016).

[10] İ. Akkurt, S. Emıkönel, F. Akarslan, K. Günoğlu, Ş. Kilinçarslan, İ.S. Üncü, Acta Phys. Pol. A 128, B-53 (2015).

[11] I. Akkurt, C. Basyigit, S. Kilincarslan, B. Mavi, A. Akkurt, Cem. Concrete Composit. 28, 153 (2006).

[12] I. Akkurt, Ann. Nucl. En. 36, 1702 (2009).

[13] T. Uygunoglu, I. Gunes, W. Brostowc, Mater. Res. 18, 1188 (2015).

[14] I. Akkurt, K. Gunoglu, S.S. Arda, Sci. Technol. Nucl. Install. 2014, 186798 (2014). 